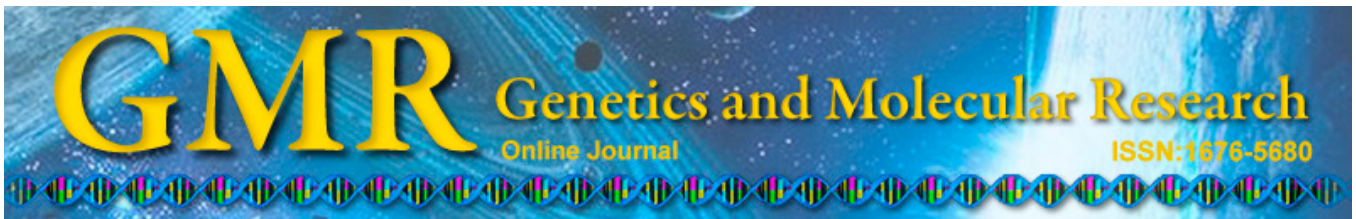

\title{
Breaking dormancy in freshly matured seeds of Elymus sibiricus, an important forage grass in the Tibetan Plateau
}

\author{
J.Q. Zhang and Y.R. Wang \\ State Key Laboratory of Grassland Agro-Ecosystems, School of Pastoral \\ Agriculture Science and Technology, Lanzhou University, Lanzhou, China \\ Corresponding author: Y.R. Wang \\ E-mail: wangyanrong2014@126.com
}

Genet. Mol. Res. 14 (3): 11109-11118 (2015)

Received January 21, 2015

Accepted June 6, 2015

Published September 22, 2015

DOI http://dx.doi.org/10.4238/2015.September.22.4

\begin{abstract}
Elymus sibiricus L. is an important forage grass widely distributed in Asia and is usually a dominant species on Tibetan Plateau alpine grasslands. Here, we used the seed development indices of 1000 seed weight, seed moisture content, and seed viability to compare the seed characteristics at 10, 20,30, 40, 50, and 60 days after anthesis (DAA) in five populations of E. sibiricus growing in Gannan, China. Additionally, seeds collected at 60 DAA were air-dried for one month, and the primary germination percentage (GP) was determined in the laboratory. Treatment of seeds with $0.2 \% \mathrm{KNO}_{3}, 100 \mathrm{mg} / \mathrm{L}$ cytokinin, and $500 \mathrm{mg} / \mathrm{L} \mathrm{GA} 3$ were tested for their effects on dormancy. A primary GP of $16 \%$ was found after $12 \mathrm{~d}$ of $15 / 25^{\circ} \mathrm{C}$ incubation, with no differences among the five populations. The 1000 seed weight and seed viability steadily increased and moisture content continuously fell with DAA. The optimal harvest time for E. sibiricus in an alpine pasture was 50 DAA. No effect on dormancy was found after treating seeds with $0.2 \% \mathrm{KNO}_{3}$ or $100 \mathrm{mg} / \mathrm{L}$ cytokinin; however, a low concentration of $\mathrm{GA}_{3}$ induced a prompt and synchronized germination. Freshly matured E. sibiricus seeds were classified to be in non-deep physiologically
\end{abstract}


dormant. Treatment of seeds with $\mathrm{GA}_{3}$ before sowing enhanced the emergence speed and seedling uniformity in E. sibiricus.

Key words: Elymus sibiricus; Breaking dormancy; $\mathrm{GA}_{3} ; \mathrm{KNO}_{3}$; Cytokinin

\section{INTRODUCTION}

Elymus L. is the largest genus in the tribe Triticeae, with approximately 150 species worldwide and 80 species in China, and is distributed across most temperate regions (Dewey, 1984). Elymus sibiricus L. (Siberian wild rye) is a perennial herbaceous forage grass with a geographic distribution that extends from Sweden to Japan and even to parts of Alaska and Canada; it is widely distributed across northern Asia (Bowden and Cody, 1961). E. sibiricus mostly grows on grasslands, under bushes, along riverbanks, on mountain slopes, and in swales at altitudes of $1000 \mathrm{~m}$ to $5000 \mathrm{~m}$ above sea level (Lu, 1993).

In China, E. sibiricus is distributed in northwest and southwest regions, and is particularly prevalent on the Qinghai-Tibet Plateau (Kuo, 1987). Natural populations of E. sibiricus from the Qinghai-Tibet Plateau show great geographic and morphological variability, particularly with regard to spike length, spike and culm color, number of spikelets/spikes, height, and length and width of leaves (Yan et al., 2006).

E. sibiricus is one of the most valuable forage grasses in alpine regions and is characterized by resistance to cold, drought, pests, and diseases. These characteristics also make this species valuable as a genetic resource for improving cereal crops. The sowing of cereal crops can significantly benefit the restoration of degraded grasslands and the construction of artificial pastures for yaks, sheep, and horses (Chen and Jia, 2002; Clayton et al., 2006). Since 2003, a national project on pasture rehabilitation has been underway in northwest China. Oversowing plays an economically important part of the restoration of degraded and overgrazed grasslands. E. sibiricus is one of the key species in the government list for the "grazing withdrawal and management of grassland" project.

Seed dormancy is the inability of viable mature seeds to germinate and produce normal seedlings under adequate conditions, even in the laboratory (Simpson, 1990). Dormancy in seeds significantly affects seed harvest and storage, adaptation to adverse environments, and germplasm propagation. Baskin and Baskin (1989) reported that the seeds of many plant species are dormant at maturity and are unable to germinate under a broad set of environmental conditions. This phenomenon poses a serious problem when a productive need for synchronous germination is not met. Prompt and synchronous germination and early seedling growth can improve seed efficiency by increasing the percentage of seedlings that meet acceptable growth parameters (Mexal and Fisher, 1987; Mexal and South, 1991). A high level of dormancy after harvest can also be a severe ecological problem for the reestablishment of grassland. Therefore, overcoming seed dormancy is an important component of efficient and cost-effective seedling production. Grasses grow in alpine areas and their seeds usually ripen under humid conditions. Under these conditions, it is advantageous to a species to have high levels of seed dormancy in order to prevent pre-harvest sprouting. A better understanding of the effects of plant hormones on breaking dormancy, inducing germination, and encouraging early seedling growth may lead to the development of pre-sowing treatments that promote accelerated and more uniform seedling growth in response to excess humidity and moisture. 
The aims of this study were to investigate: (1) the dynamics of seed development in $E$. sibiricus, from seed setting to physiological maturation and ripening, (2) the appropriate harvest time for E. sibiricus on alpine grasslands, and (3) the dormancy characteristics and methods for breaking dormancy in freshly matured E. sibiricus seeds. Habitat and environmental effects on seed development and dormancy were also examined. This study should aid identification of appropriate methods for application to freshly matured E. sibiricus seeds before sowing as part of a program to reseed artificial grasslands or reestablish degraded grasslands.

\section{MATERIAL AND METHODS}

\section{Sampling place}

Basic geographic information on the five populations of E. sibiricus from the Gannan Tibetan Autonomous Prefecture, Gansu Province, China, is given in Table 1.

Table 1. Seed collected site and their geographical information of 5 populations of Elymus sibiricus.

\begin{tabular}{lllccc}
\hline Seed collection sites & Abb. & Habitat & Altitude (m.a.s.l) & Longitude (E) & Lantitude (N) \\
\hline Ma'ai town of Luqu county & MA & Seeded grassland & 3010 & $102^{\circ} 28^{\prime}$ & $34^{\circ} 35^{\prime}$ \\
Larenguan commune of Luqu county & LRG & Forestry & 3030 & $102^{\circ} 29^{\prime}$ & $34^{\circ} 21^{\prime}$ \\
Luqu county Grassland Station & LQGS & Riverside & 3094 & $102^{\circ} 34^{\prime}$ & $34^{\circ} 34^{\prime}$ \\
Nimalong commune of Xiahe county & NML & Shrub & 3174 & $102^{\circ} 51^{\prime}$ & $34^{\circ} 49^{\prime}$ \\
Maqu county Grassland Station & MQGS & Seeded grassland & 3500 & $100^{\circ} 01^{\prime}$ & $33^{\circ} 32^{\prime}$ \\
\hline
\end{tabular}

\section{Sampling time and seed moisture content}

Three hundred ears of E. sibiricus were labeled in the field on July 20, 2008 at the very beginning of the flowering stage. Thirty ears from each population were harvested using scissors on July 30 [10 days after anthesis (DAA)], August 10 (20 DAA), August 20 (30 DAA), August 30 (40 DAA), September 10 (50 DAA), and September 20 (60 DAA), 2008, i.e., six sampling times with 10-day intervals. The ears were bagged and taken back to the laboratory. The seeds were detached from the petioles and immediately weighed on an analytical balance with an accuracy of $0.1 \mathrm{mg}$ (CPA224S, SATORUS, Germany). The fresh weight of the seeds was recorded. Three replicates of each population were obtained, with 10 ears in each replicate. The seeds were air-dried for one month. The dried weight was obtained and recorded. Seed moisture content was calculated according to the following formula:

$$
\text { Moisture content }(\%)=\left(\mathrm{w}_{\mathrm{f}}-\mathrm{w}_{\mathrm{d}}\right) \times 100 / \mathrm{w}_{\mathrm{f}}
$$

where $w_{\mathrm{f}}$ denotes the fresh weight, and $w_{\mathrm{d}}$ represents the dried weight.

After the moisture content was determined, the seeds were thoroughly mixed, cleaned, and stored at room conditions until use. 


\section{Calculating 1000-seed weight and viability testing}

The 1000-seed weight was calculated according to the procedure approved by the International Seed Testing Association (ISTA, 1999). In detail, the method for calculating 1000 seed weight involved taking 100 seeds from each replicated seed sample. Each batch of 100 seeds was weighed and the mean was calculated. Based on the mean weight of 100 seeds, the 1000-seed weight for each sample was calculated (i.e., 10X).

\section{Test of viability and percentage of dormancy (\%)}

A staining buffer solution (2,3,5-triphenyl tetrazolium chloride) was made according to the method described in ISTA (1999). The pure seed fraction was thoroughly mixed, and four replicates of the 100 seeds were randomly selected. Each replicate of 100 seeds was fully immersed in distilled water for $18 \mathrm{~h}$ and left completely imbibed. A longitudinal cut approximately three-quarters of the length of the endosperm was made through the embryonic axis. Each replicate of 100 cut seeds was then fully immersed in $1 \%$ tetrazolium salt for $18 \mathrm{~h}$ in a $30^{\circ} \mathrm{C}$ growth chamber. Complete or partial red staining of the cut surface indicated a viable seed; unstained seeds were inviable seeds. The viability rate was calculated as viable seeds per 100 seeds. The percentage of dormancy was considered to be the proportion of viable seeds minus that of germinating seeds for each sample.

\section{Initial germination percentage of seeds at $60 \mathrm{DAA}$ (control)}

Four replicates of 100 seeds were taken randomly from the well-mixed seeds. The primary germination capacity of seeds at 60 DAA was tested according to the method described by ISTA (1999). The primary germination conditions set for E. sibiricus by the Rules for Forage Seed Testing (NQTBC, 2001) were used in this study. Primary germination capacity was tested by placing the seeds on top of two layers of moistened filter paper in Petri dishes in a growth chamber at $15 / 25^{\circ} \mathrm{C}$ (alternating temperature with $8 \mathrm{~h}$ at the higher temperature and $16 \mathrm{~h}$ at the lower), and illuminated by an incandescent light bulb (700 lx) with light all day. The seeds were scored as germinated when the radical emerged. Germination was monitored at 1- or 2-day intervals until no seeds had germinated for more than 5 days (unless specified otherwise). The final germination percentage was determined after 12 days. The germinated seeds were removed from the Petri dishes after scoring. At the end of the germination period, the germination percentage for each Petri dish was calculated as the germinated seeds in relation to the sown seeds.

\section{Methods for seed dormancy break}

\section{$0.2 \% \mathrm{KNO}_{3}$ treatment}

Seeds were placed on two layers of filter paper saturated with $0.2 \%$ potassium nitrate at the beginning of the test. Water was used for moistening thereafter. 


\section{0-mg/L gibberellic acid $\left(G_{3}\right)$ treatment}

A 500-mg/L GA solution was prepared by dissolving $500 \mathrm{mg} \mathrm{GA}$ (Sangon Biotech, Shanghai) in $5 \mathrm{~mL}$ ethanol, and then diluted to $1 \mathrm{~L}$ with distilled water at the beginning of the test. The filter paper was soaked in the solution at the beginning of the test, water was used for moistening thereafter.

\section{0-mg/L cytokinin treatment}

A 100-mg/L cytokinin solution was prepared by dissolving 100 mg KT (Sangon Biotech, Shanghai) in $5 \mathrm{~mL}$ ethanol, and then diluted to $1 \mathrm{~L}$ with distilled water at the beginning of the test. The filter paper was soaked in the solution at the beginning of the test, water was used for moistening thereafter.

\section{Data analysis}

Statistical analysis of the data was conducted using SPSS 17.1 for Windows (SPSS, USA). One-way ANOVA was used to compare the means of seed populations, and Duncan's multiple range test was used to compare means at a significance level of $5 \%$. Seed moisture content and seed viability are reported as means \pm standard error.

\section{RESULTS}

\section{Moisture content and 1000-seed weight}

Seed moisture content in E. sibiricus decreased from an average of $74.4 \%$ at 10 DAA to $17.9 \%$ at 60 DAA. On an average, seed moisture content decreased by $15 \%$ at every 10 day interval. The greatest decreases in moisture content were recorded at the 20- to 30-DAA interval and the 40- and 50-DAA interval (Table 2).

Table 2. Seed moisture content in different DAA of 5 populations of Elymus sibiricus.

\begin{tabular}{lccccrrr}
\hline Collecting sites & \multicolumn{7}{c}{ Seed moisture content (\%) } \\
\cline { 2 - 7 } & 10 DAA & 20 DAA & 30 DAA & 40 DAA & 50 DAA & 60 DAA & 10 DAA \\
\hline MA & $72.1 \pm 0.667$ & $64.8 \pm 1.797$ & $45.7 \pm 0.795$ & $38.6 \pm 1.542$ & $21.5 \pm 0.869$ & $16.9 \pm 0.521$ & $72.1 \pm 0.667$ \\
LRG & $78.1 \pm 0.839$ & $68.9 \pm 0.576$ & $49.2 \pm 0.569$ & $39.4 \pm 0.832$ & $22.6 \pm 0.710$ & $20.1 \pm 0.752$ & $78.1 \pm 0.839$ \\
LQGS & $71.9 \pm 0.707$ & $63.8 \pm 0.555$ & $45.1 \pm 0.769$ & $37.9 \pm 0.715$ & $21.1 \pm 0.555$ & $16.2 \pm 0.719$ & $71.9 \pm 0.707$ \\
NML & $72.3 \pm 0.801$ & $65.2 \pm 1.135$ & $45.9 \pm 0.587$ & $37.3 \pm 0.537$ & $20.9 \pm 0.932$ & $16.5 \pm 0.683$ & $72.3 \pm 0.801$ \\
MQGS & $77.6 \pm 0.919$ & $68.1 \pm 0.998$ & $48.5 \pm 1.111$ & $38.2 \pm 1.148$ & $21.9 \pm 1.027$ & $19.6 \pm 1.098$ & $77.6 \pm 0.919$ \\
\hline
\end{tabular}

All data in the table means average value \pm standard error; $\mathrm{MA}=\mathrm{Ma}$-ai town of Luqu county; $\mathrm{LRG}=$ La-ren-guan town of Luqu county; LQGS = Grassland Station of Luqu county; NML = Ni-ma-long town of Xiahe county; and MQGS $=$ Grassland Station of Maqu county; DAA = days after anthesis.

The 1000-seed weight at 10 DAA averaged to $1.85 \mathrm{~g}$ for the five populations. This average steadily increased up to $60 \mathrm{DAA}(3.22 \mathrm{~g})$. Regarding moisture content, the 20- to 30-DAA and the 30- to 40-DAA intervals showed the largest changes. The 1000-seed weight increased by approximately $25 \%$ at each of these intervals, whereas, at other intervals, it was only about $10 \%$ (Table 3 ). 
Table 3. One-thousand-seed weight in different DAA of 5 populations of Elymus sibiricus.

\begin{tabular}{lcccccc}
\hline Collecting sites & \multicolumn{5}{c}{ One thousand seed weight $(\mathrm{g})$} \\
\cline { 2 - 6 } & 10 DAA & 20 DAA & 30 DAA & 40 DAA & 50 DAA & 60 DAA \\
\hline MA & 1.94 & 2.23 & 2.68 & 3.04 & 3.19 & 3.22 \\
LRG & 1.76 & 1.88 & 2.12 & 2.44 & 2.92 & 3.01 \\
LQGS & 1.89 & 2.19 & 2.49 & 2.98 & 3.09 & 3.18 \\
NML & 1.91 & 2.20 & 2.55 & 3.14 & 3.16 & 3.20 \\
MQGS & 1.77 & 1.92 & 2.32 & 2.85 & 2.98 & 3.06 \\
\hline
\end{tabular}

All data in the table means average value \pm standard error; MA = Ma-ai town of Luqu county; LRG = La-ren-guan town of Luqu county; LQGS = Grassland Station of Luqu county; NML = Ni-ma-long town of Xiahe county; and MQGS = Grassland Station of Maqu county; DAA = days after anthesis.

Seed viability increased steadily from 10 DAA (11\%) to 60 DAA (96\%) with an average increase of about $20 \%$ for each 10-day interval. The largest increase occurred between 10 and 20 DAA (approximately 25\%) and the lowest between 50 and 60 DAA (5\%; Table 4).

Table 4. Seed viability in different DAA of 5 populations of Elymus sibiricus.
\begin{tabular}{lrccrrr}
\hline Collecting sites & \multicolumn{7}{c}{ Seed viability (\%) } \\
\cline { 2 - 7 } & $10 \mathrm{DAA}$ & $20 \mathrm{DAA}$ & $30 \mathrm{DAA}$ & 40 DAA & 50 DAA & 60 DAA \\
\hline MA & $9 \pm 2.273$ & $38 \pm 4.203$ & $61 \pm 4.416$ & $77 \pm 4.223$ & $87 \pm 3.536$ & $95 \pm 2.345$ \\
LRG & $0 \pm 0.000$ & $26 \pm 3.697$ & $49 \pm 4.163$ & $62 \pm 5.874$ & $78 \pm 2.483$ & $88 \pm 2.887$ \\
LQGS & $12 \pm 3.651$ & $41 \pm 5.944$ & $63 \pm 7.071$ & $81 \pm 7.257$ & $91 \pm 4.397$ & $98 \pm 1.826$ \\
NML & $10 \pm 1.291$ & $40 \pm 1.683$ & $65 \pm 4.916$ & $85 \pm 3.808$ & $90 \pm 3.162$ & $99 \pm 0.408$ \\
MQGS & $0 \pm 0.000$ & $28 \pm 6.325$ & $53 \pm 6.976$ & $69 \pm 9.557$ & $85 \pm 8.287$ & $92 \pm 3.367$
\end{tabular}

All data in the table means average value \pm standard error; MA = Ma-ai town of Luqu county; LRG = La-ren-guan town of Luqu county; LQGS = Grassland Station of Luqu county; NML = Ni-ma-long town of Xiahe county; and MQGS $=$ Grassland Station of Maqu county; DAA $=$ days after anthesis.

\section{Initial germination percentage and effect of treatment with $0.2 \% \mathrm{KNO}_{3}$ or $100 \mathrm{mg} / \mathrm{L}$ cytokinin}

An initial germination percentage of $11 \%$ was found for E. sibiricus seeds harvested at 60 DAA from the five populations. The viability rate minus the initial GP was high (85\%). Treatment of seeds with $0.2 \% \mathrm{KNO}_{3}$ plus pre-chilling or with $100 \mathrm{mg} / \mathrm{L}$ cytokinin increased the GP only by about 5\%; there was no difference in effect between the two treatments Thus, these treatments had little success in increasing the GP. In contrast, treatment of seeds with $500 \mathrm{mg} / \mathrm{L} \mathrm{GA}_{3}$ stimulated germination and $95 \%$ of seeds had germinated by the end of the 12 day incubation period. The increased percentage of germination after $\mathrm{GA}_{3}$ treatment was significant compared to $0.2 \% \mathrm{KNO}_{3}$, and $100 \mathrm{mg} / \mathrm{L}$ cytokinin (Figures 1 and 2).

\section{DISCUSSION}

A relatively stable 1000-seed weight is an important parameter of seeds at maturity. The 1000-seed weight in this study is in agreement with previously reported estimates (3.5 to $3.9 \mathrm{~g}$ ) from E. sibiricus in China (Chen, 2001). Seeds grown in alpine areas and harvested at 60 DAA had reached their physiological maturity based on the 1000-seed weight. 


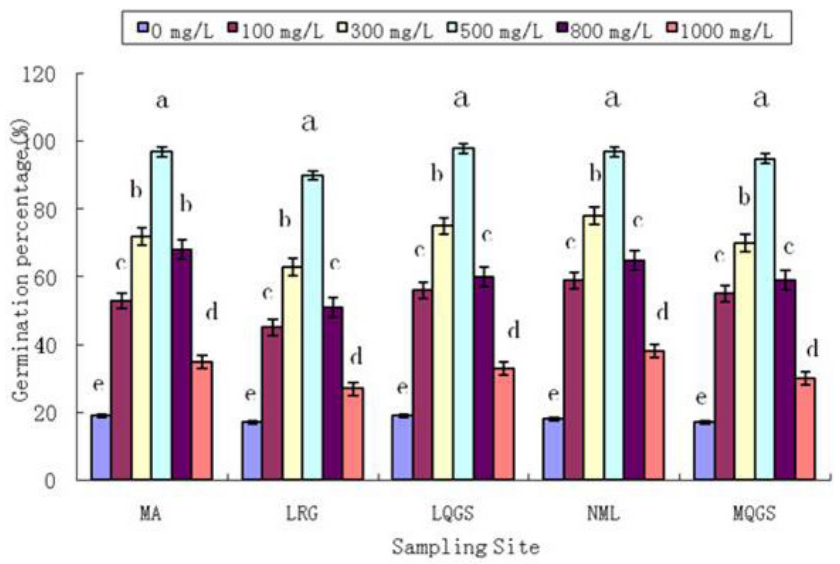

Figure 1. Effect of different concentration solution of GA3 on the break of Elymus sibiricus seed dormancy for different sources. $M A=$ Ma-ai town of Luqu county; $L R G=$ La-renguan town of Luqu county; LQGS = Grassland Station of Luqu county; NML = Ni-malong town of Xiahe county; and MQGS = Grassland Station of Maqu county. $\mathrm{DAA}=$ days after anthesis.

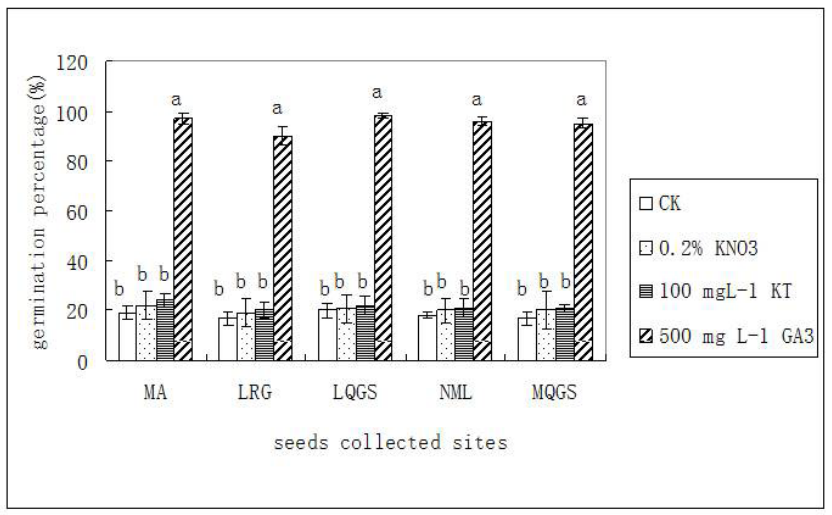

Figure 2. Germination percentage of 5 populations of Elymus sibiricus under different treatments harvested 60 DAA. MA = Ma-ai town of Luqu county; LRG = La-renguan town of Luqu county; LQGS = Grassland of Luqu county; $\mathrm{NML}=\mathrm{Ni}$-malong town of Xia he county; and MQGS $=$ Grassland Station of Maqu county. DAA = days after anthesis.

The freshly matured seeds at 60 DAA from all five populations had a high level of seed dormancy (Figure 1). This characteristic favors the propagation and spread of the plants in alpine areas. Most species in unstable alpine habitats have the potential to form persistent seed banks. This ability enables these species to delay germination until favorable conditions are present in the environment, thereby increasing the likelihood for the establishment of seedlings. Seeds in alpine grassland also often possess dormancy mechanisms that prevent germination under conditions that are unsuitable for seedling establishment (Fenner, 1985). As a result, these seeds are incorporated into a seed bank, a reserve of viable seeds in the soil and on its surface (Roberts, 1981). Persistent seed banks are an important life history traits for 
unstable alpine species. Persistent seed banks allow alpine species to control their germination for more favorable years or seasons (Arroyo et al., 1999) and compensate for seasons with poor rates of reproduction and establishment. The formation of persistent seed banks can be viewed as a typical risk spreading strategy (Jurado and Flores, 2005), enabling plants to cope with harsh and unpredictable environmental conditions. Generally, persistent seed banks have traits that are specific for the particular species, although these may be modified by environmental conditions, such as soil and climate conditions (Fenner and Thompson, 2005). Species in the genus Carex growing in alpine wet areas have a high level of seed dormancy for adaptation to the harsh environment (Schütz, 2000; Kettenring and Galatowirsch, 2007). Similarly, seeds of $E$. sibiricus that are coated with 303-JB seedling-accelerating reagents (which contain plant growth hormones and cold-resistance reagents) can germinate synchronously and uniformly under the climatic conditions of the Qinghai and Tibetan Plateaus (Xu et al., 2002). The seeds of E. dahuricus that have been stored at normal temperature for one year have a high degree of dormancy. However, after two to three years of storage, the seeds exhibit their highest vigor (around 90\%) (Zhang et al., 2008). Germination at the right time and in the right place largely determines the probability of seedling survival to maturity (Thompson, 1973).

\section{Class of dormancy of tested seeds}

Baskin and Baskin (2004) proposed a modified classification system for seed dormancy: physiological dormancy, morphological dormancy, morpho-physiological dormancy, physical dormancy, and a combination of physiological and physical dormancy. This system of classifying seed dormancy enables the identification of the class of dormancy in seeds by investigating their responses in terms of germination to various pretreatments. The dormancy of seeds refers to the absence of the capacity to germinate in a specified period of time under any combination of normal physical environmental factors (Baskin and Baskin, 2004). Dormancy is still primarily measured in terms of (non-)germination. The proportion of viable seeds in the tested populations of E. sibiricus was $95 \%$ at 60 DAA, and the seeds collected at 60 DAA during the germination period imbibed water normally. The standard germination test, viability test, and $\mathrm{GA}_{3}$ pre-moistened substrate treatment test applied to the freshly matured E. sibiricus seeds showed that seed dormancy in E. sibiricus belonged to the non-deep physiological dormancy class. In spite of this, the results presented here should be valuable in facilitating $E$. sibiricus seed germination and in providing a better understanding of some of the ecological adaptations of alpine seeds. This dormancy mechanism allows a species to synchronize its germination under favorable environmental conditions, increasing its probability of survival and establishment (Baskin and Baskin, 1998). For freshly matured E. sibiricus seeds, GA 3 pretreatment should be considered a good pre-sowing strategy for breaking their dormancy.

The seeds of the E. sibiricus populations failed to germinate under control conditions. They also failed to germinate in moist pre-chilling treatments under continuous light conditions. Many seeds with physiological dormancy have insufficient levels of endogenous gibberellins to allow germination. Here, this deficiency was circumvented by the addition of exogenous gibberellin which broke dormancy and caused germination. The seed GP in the five populations was promoted by soaking in $\mathrm{GA}_{3}$ solution. Thus, seed dormancy in E. sibiricus is linked to an insufficient level of endogenous gibberellins. Cytokinins are involved in the mobilization of storage reserves for use during germination in cereals (Fincher, 1989; Hocart and 
Letham, 1990). During germination, cytokinins may significantly offset the effect of germination inhibitors (Khan, 1975). However, a general synergistic relationship seems to exist between cytokinins and gibberellins in the regulation of dormancy and germination. Gibberellic acid (gibberellins) sensitivity increases in seeds during the breaking of non-deep physiological dormancy (Finch-Savage and Leubner-Metzger, 2006). Previous studies have attempted to correlate dormancy levels with hormone interactions (Kucera et al., 2005). Changes in the content of abscisic acid, GA, and cytokinins have been examined in the seeds of many species, but no consistent correlation between dormancy level and hormone content has been established (Khan and Samimy, 1982).

Widely distributed plant species need to be able to adapt to a broad range of environmental conditions to maintain their geographic distribution. Consequently, many widespread species have high genetic diversity and have evolved into a series of ecological races or exhibit considerable phenotypic plasticity. However, the E. sibiricus populations used in this experiment were sampled from a narrow ecogeographic area of distribution, and were typical representatives of plants in this area.

In conclusion, an effective strategy for breaking seed dormancy and enhancing the seed germination rate of E. sibiricus is through a combination of a low concentration of $\mathrm{GA}_{3}$ and a continuous photoperiod. The non-deep physiological dormancy in this species is consistent with the conditions in its alpine habitats. These traits give the species a critical capability of controlling the timing of emergence, seedling establishment, and the spread of offspring.

At different times after anthesis, significant differences were found in seed development in E. sibiricus. It is likely that different habitats also have an important effect on seed characteristics. The seeds from the five populations of E. sibiricus reached physiological maturity between 45 and 50 DAA, and a considerable level of dormancy was observed in all habitats. Treatment with a low concentration of $\mathrm{GA}_{3}$ effectively broke this dormancy.

\section{ACKNOWLEDGMENTS}

Research supported by the Natural Basic Research Program (“973" program) of China (\#2007 CB108904), the Agricultural Applying and Development Project of Biotechnology of Gansu Province, China (\#GNSW-2011-16), the National Natural Science Foundation of China (\#31101759), the Natural Science Foundation of China (\#31302023), and the Fundamental Research Funds for Central Government (\#lzujbky-2013-81).

\section{REFERENCES}

Arroyo MTK, Cavieres LA, Castor C and Humana AM (1999). Persistent soil seed bank and standing vegetation at a high alpine site in the central Chilean Andes. Oecologia 119: 126-132.

Baskin CC and Baskin JM (1989). Physiology of dormancy and germination in relation to seed bank ecology. Ecology of soil seed banks (Leck MA, Parker VT and Simpson RL, eds.). Academic Press, San Diego, 53-56.

Baskin CC and Baskin JM (1998). Seeds. Ecology, biogeography and evolution of dormancy and germination. Academic Press, San Diego.

Baskin JM and Baskin CC (2004). A classification system for seed dormancy. Seed Sci. Res. 14: 1-16

Bowden WM and Cody WJ (1961). Recognition of Elymus sibiricus L. from Alaska and the district of Mackenzie. Bull. Torrey Bot. 88: 153-155.

Chen BS (2001). Cultivation for forage grasses and fodders in China. P.R. China Agricultural Press, Beijing.

Chen MJ and Jia SX (2002). China forage plants. China Agricultural Press, Beijing. 
Clayton WD, Harman KT and Williamson H (2006). GrassBase-the online world grass flora. Available at [http://www. kew.org/data/grass/clb.html].

Dewey DR (1984). Cytogenetics of Elymus sibiricus and its hybrids with Agropyron tauri, Eylmus canadensis, and Agropyron caninus. Bot. Gaz. 135: 80-87.

Fenner M (1985). Seed ecology. Chapman and Hall, New York.

Fenner M and Thompson K (2005). The ecology of seeds. University Press, Cambridge.

Fincher GB (1989). Molecular and cellular biology associated with endosperm mobilization in germinating cereal grains. Annu. Rev. Plant Physiol. Plant Mol. Biol. 40: 305-346.

Finch-Savage WE and Leubner-Metzger G (2006). Seed dormancy and the control of germination. New Phytol. 171: 501-523.

Hocart CH and Letham DS (1990). Biosynthesis of cytokinin in germinating seeds of Zea mays. J. Exp. Bot. 41: 15251528.

International Seed Testing Association (ISTA) (1999). International rules for seed testing. Seed Sci. Tech. 24: 167-176.

Jurado E and Flores J (2005). Is seed dormancy under environmental control or bound to plant traits? J. Veg. Sci. 16: 551-564.

Kettenring KM and Galatowirsch SM (2007). Temperature requirement for dormancy break and germination vary greatly among 14 wet land Carex species. Aquat. Bot. 87: 209-220.

Khan AA (1975). Primary, preventative and permissive roles of hormones in plant systems. Bot. Rev. 41: 391-420.

Khan AA and Samimy C (1982). Hormones in relation to primary and secondary seed dormancy. In: The physiology and biochemistry of seed development, dormancy and germination (Khan AA, ed.). Elsevier Biomedical Press, Amsterdam, 203-241.

Kucera B, Cohn MA and Leubner-Metzger G (2005). Plant hormone interactions during seed dormancy release and germination. Seed Sci. Res. 15, 281-307.

Kuo BZ (1987). Flora reipublicae popularis sinciae, Science Press, Beijing.

Lu BR (1993). Meiotic studies of Elymus nutans and E. jacquemontii (Poaceae: Triticeae) and their hybrids with Pseudoroegneria spicata and seventeen Elymus species. Plant System. Evol. 186: 193-212.

Mexal JG and Fisher JJ (1987). Size hierarchy in conifer seedbeds. I. Time of emergence. New For. 1: 187-196.

Mexal JG and South DB (1991). Bareroot seedling culture. In: Forest regeneration manual, Kluwer Academic Publishers, Dordrecht/Boston/London 433, 89-115.

National Quality Technology Bureau of China (NQTBC) (2001). Rules for forage seed testing (Duryea ML and Dougherty PM, eds.). China Standard Press, Beijing, 33-42.

Roberts HA (1981). Seed banks in soils. Adv. Appl. Biol. 6: 1-55.

Schütz W (2000). Ecology of seed dormancy and germination in sedges (Carex). Persp. Plant Ecol. Evol. Syst. 311: 67-89. Simpson GM (1990). Seed dormancy in grasses. Cambridge University Press, New York.

Thompson PA (1973). Seed germination in relation to ecological and geographical distribution. Taxonomy and ecology (Heywood VA, ed.). Academic Press, London, 93-119.

Xu BM, Li YD, Wei YN and Li BS (2002). Studies on seed germination characteristics and raising seed vigour of Elymus nutans. Seed 4: 1-4.

Yan XB, Guo YX and Zhou H (2006). Genetic patterns of ten Elymus species from Tibet and inner Mongolian plateaus. Grass Forage Sci. 61: 398-404.

Zhang DH, Yun JF, Shi FL and Liu F (2008). Measurement of seed deterioration and vigor of Elymus dahuricus with different storage time. Pratacultural Sci. 4: 116-118. 